\title{
NUMERICAL ANALYSIS ON THE INFLUENCE OF DYNAMIC SOIL- STRUCTURE INTERACTION IN SORIA ARCH DAM: A CASE STUDY
}

\author{
J.C. Galván, L.A. Padrón, J.J. Aznárez, O. Maeso ${ }^{1}$ \\ ${ }^{1}$ Instituto Universitario de Sistemas Inteligentes y Aplicaciones Numéricas en Ingeniería \\ (SIANI) Universidad de Las Palmas de Gran Canaria \\ Edificio Central del Parque Científico y Tecnológico \\ Campus Universitario de Tafira, 35017, Las Palmas de Gran Canaria, Spain \\ \{juancarlos.galvan, luis.padron, juanjose.aznarez, orlando.maeso\}@ulpgc.es
}

\begin{abstract}
Soria arch dam and reservoir is the largest infrastructure of this type that exists in the Canary Islands both in capacity and height which is located in the Island of Gran Canaria. The goal of this paper is the development of a numerical model for the analysis of the dynamic and seismic behavior of this arch dam. To do so the effects of the ground motion and of the canyon geometry on the dynamic response of the arch dam are studied in this paper. The seismic response of the arch dam subject to time harmonic shear waves impinging the dam site with a horizontal upstream and cross-stream free-field ground surface motion is analyzed. The numerical model includes both the concrete arch dam and the surrounding area, so that soilstructure interaction phenomena can be taken into account as accurately as possible. The model is used to evaluate the magnitude of soil-structure interaction and also the influence of the accuracy of the geometrical representation of the surrounding topography on such soilstructure interaction effects. To this end, two different numerical models are built. On the one hand, a Finite Element Model of the actual geometry of the concrete dam wall is developed and used to perform a modal analysis of the fixed-base model. On the other hand, several three-dimensional frequency-domain Boundary Element models of both the concrete dam and the surrounding topography are built; all of these models include the actual geometry of the dam wall and different approximations of the surrounding soil, ranging from a very simplified straight prismatic canyon to an elaborate model of the actual topography. These BEM models are used not only to estimate compliant-base natural frequencies and mode shapes, but also to study the seismic response of the system when subjected to incident planar seismic waves. The results show that the influence of the soil-structure interaction effects on the dynamic response of the system is quite significant. It is also shown that the asymmetry of the canyon might significantly affect the seismic response of the dam wall.
\end{abstract}

Keywords: Arch dam, Boundary Element Method, dynamic soil—structure interaction. 


\section{INTRODUCTION}

Located in the south of the Island of Gran Canaria, between the municipalities of Mogán and San Bartolomé de Tirajana, the Soria dam is a concrete double-curvature arch dam. Soria arch dam and reservoir is the largest infrastructure of this type that exists in the Canary Islands both in capacity $\left(32 \mathrm{hm}^{3}\right)$ and height $(120 \mathrm{~m})$. The structure was constructed from 1962 to 1972 . It is 120 meters in height (above foundation) and with a thickness of the crown cantilever decreasing from $17.30 \mathrm{~m}$ at the base to $3 \mathrm{~m}$ at the crest. It is provided with 5 galleries inside its body [1]. Some pictures of Soria dam are shown in Figure 1.
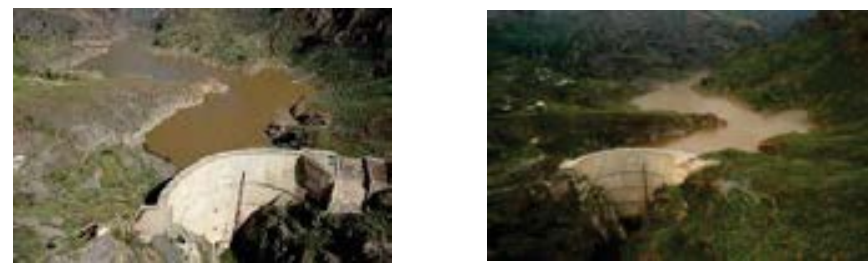

Figure 1 : Soria arch dam (Gran Canaria).

The present study aims at building a three-dimensional numerical model for the analysis of the dynamic and seismic behavior of the Soria arch dam in order to analyze the influence of the soil-structure interaction effects, and of the accuracy of the geometrical representation of the surrounding topography.

\section{METHODOLOGY}

Firstly, a geometrical model was developed consisting of two parts: the dam wall and the canyon. The geometry of the dam wall was constructed according to the information gathered from a specific study made in 1991 [2]; on the other hand, a geometrical representation of the actual canyon and surroundings was obtained from topographic information available in the databases of Gobierno de Canarias [3].

Secondly, a modal analysis was carried out. For that, a 3D finite element model of the dam wall was developed to obtain the mode shapes of vibration of the fixed-base model. Displacements along the abutments and base of the dam wall are assumed to be zero in this case (Figure 2). The finite element mesh corresponding to the geometry of the dam wall was constructed by means of 4250 tetrahedral 3D elements and 7805 nodes (Figure 3). For the Finite Element Analysis, Code_Aster was used, which is a Finite Element Analysis software engine [4].

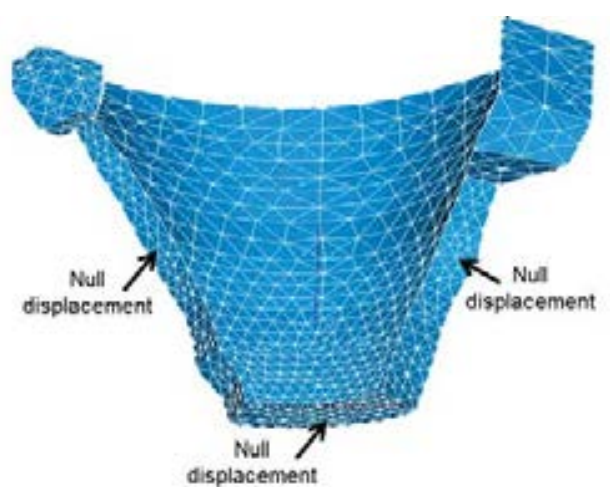

Figure 2: Boundary conditions in modal analysis. 

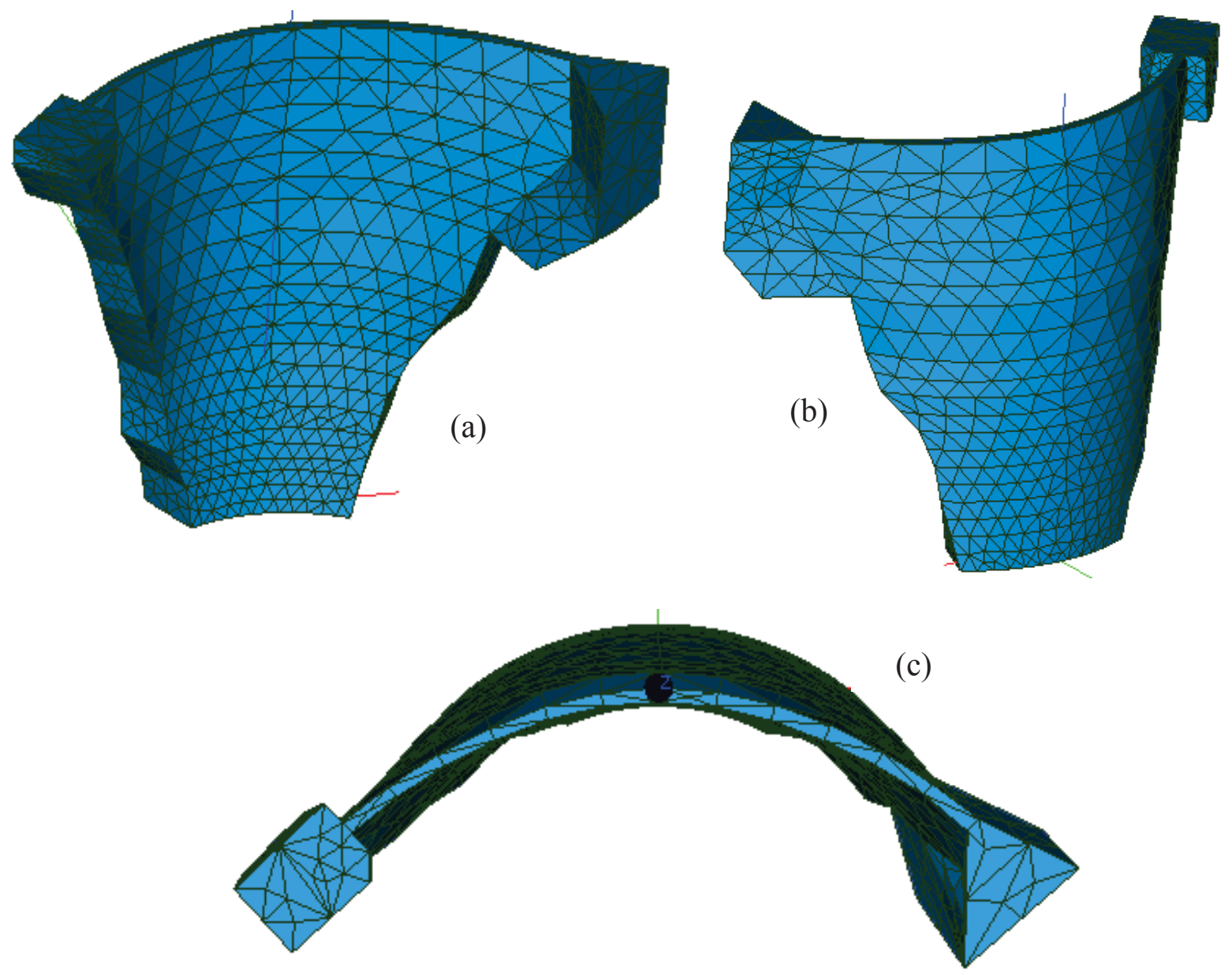

Figure 3: 3D mesh used for the FEM analysis. (a) downstream side view, (b) upstream side view and (c) top view.

Thirdly, to illustrate the differences in the dynamic response of the soil-structure system, harmonic analyses of the system, considering both fixed- and compliant-base configurations, were carried out using the multidomain Boundary Element Method (BEM) code in the frequency domain described in Maeso et al. [5,6]. Wall and surrounding ground are modelled by means of boundary integral equations discretized into boundary elements, taking into account their specific characteristics and the interaction between them by using existing compatibility and equilibrium relationships on the variables defined for structure and soil in the nodes of the contact surfaces. Nine node quadratic quadrilateral elements and six node quadratic triangular elements with a parabolic approximation are used for the boundary elements discretization. The size of the wall elements is determined by the wavelength in the dam wall while in the soil free surface it is gradually increased as the distance from the area of interest increased. The Boundary Element Method allows to take intrinsically into account the unbounded character of the soil medium, without the need of absorbing boundaries or any other mathematical artifact. On the contrary, the free-field mesh is truncated at a distance such that only the scattered wave fields are sufficiently damped. Both structure and soil are considered as solid viscoelastic materials applying in these regions Navier's equation. 
Figure 4 shows the boundary element mesh used for the fixed-base model. The influence of soil-structure interaction and of the accuracy of the geometrical representation of the surrounding topography on such soil-structure interaction effects needs to be evaluated. In order to do so, three of the BE discretizations are used. Figures 5, 6 and 7 show the actual geometry of the dam wall with different approximations of the surrounding soil, from a straight prismatic canyon with two different amounts of free-surface (Figures 5 and 6, free-surface extensions equal to two and three times the height of the dam wall, respectively) to a model of the actual topography (Figure 7, free-surface extensions equal to two times the height of the dam wall). As mentioned before, these four BEM models have been constructed by means of ninenode quadratic quadrilateral elements and six-node quadratic triangular elements where the number of nodes and elements are shown in table 1.
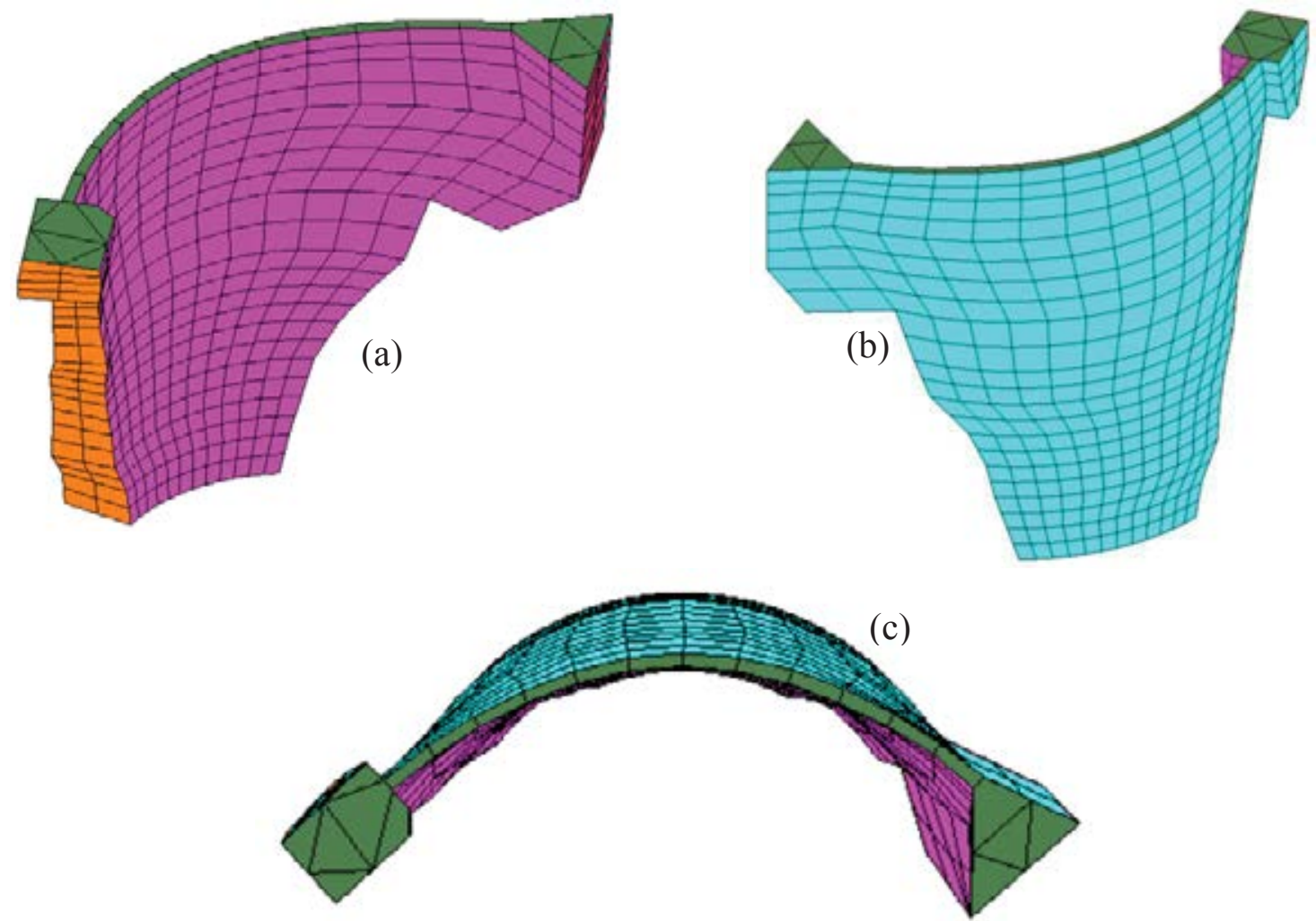

Figure 4: 3D mesh used for the BEM analysis of the dam wall. (a) Downstream side view, (b) up-stream side view and (c) top view.

\begin{tabular}{ccc}
\hline BEM models & $\begin{array}{c}\text { Number } \\
\text { of nodes }\end{array}$ & $\begin{array}{c}\text { Number of } \\
\text { elements }\end{array}$ \\
\hline Fixed base & 3228 & 733 \\
\hline Compliant base. Prismatic canyon $(\mathrm{R}=240 \mathrm{~m})$ & 8168 & 2023 \\
\hline Compliant base. Topographic canyon $(\mathrm{R}=240 \mathrm{~m})$ & 10397 & 2739 \\
\hline Compliant base. Prismatic canyon $(\mathrm{R}=360 \mathrm{~m})$ & 10408 & 2631 \\
\hline
\end{tabular}

Table 1: Number of nodes and elements in BEM models. 


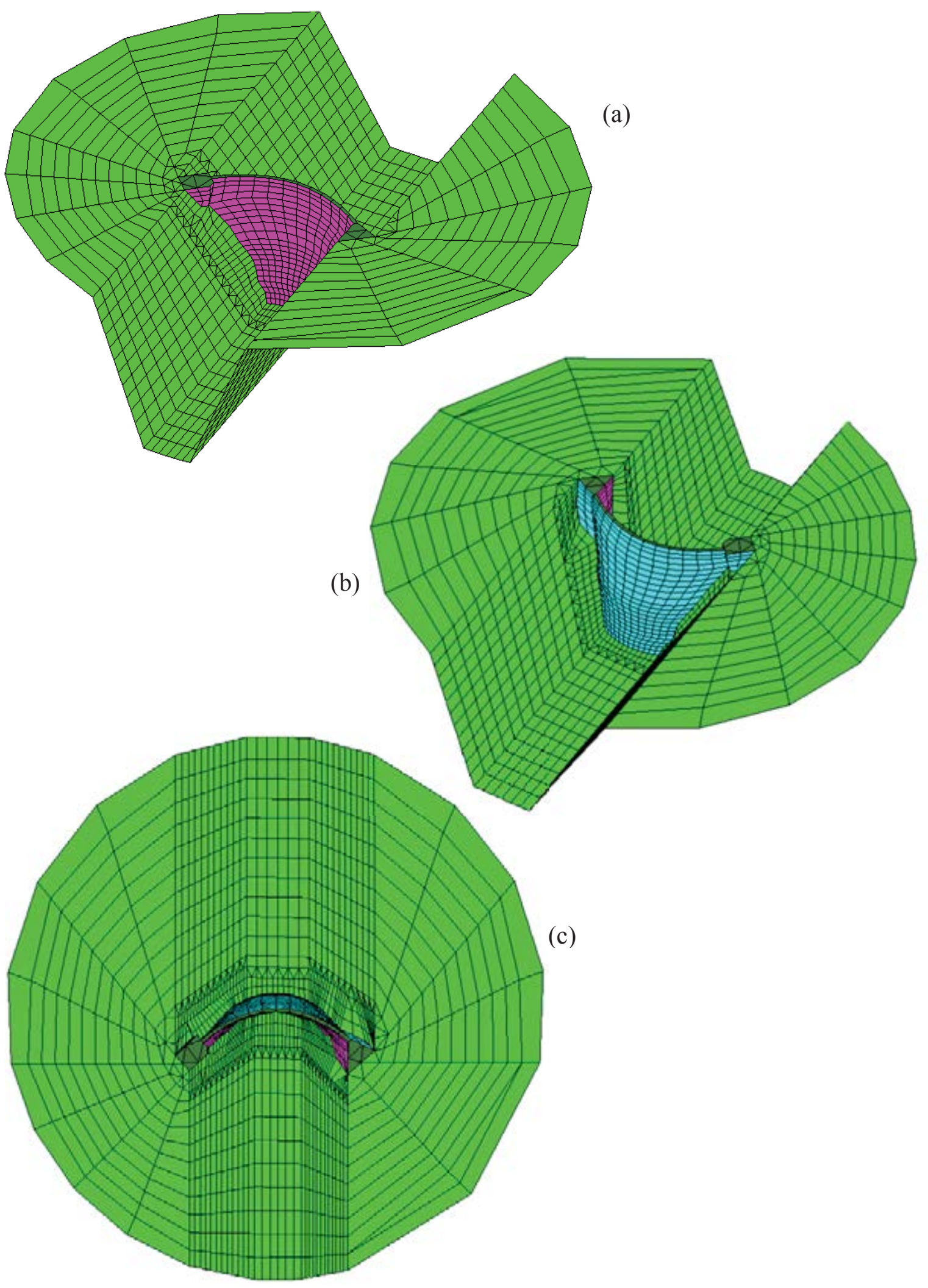

Figure 5: BE model, prismatic canyon. Extension of the free-field discretization: $240 \mathrm{~m}$. (a) Downstream side view, (b) up-stream side view and (c) top view. 


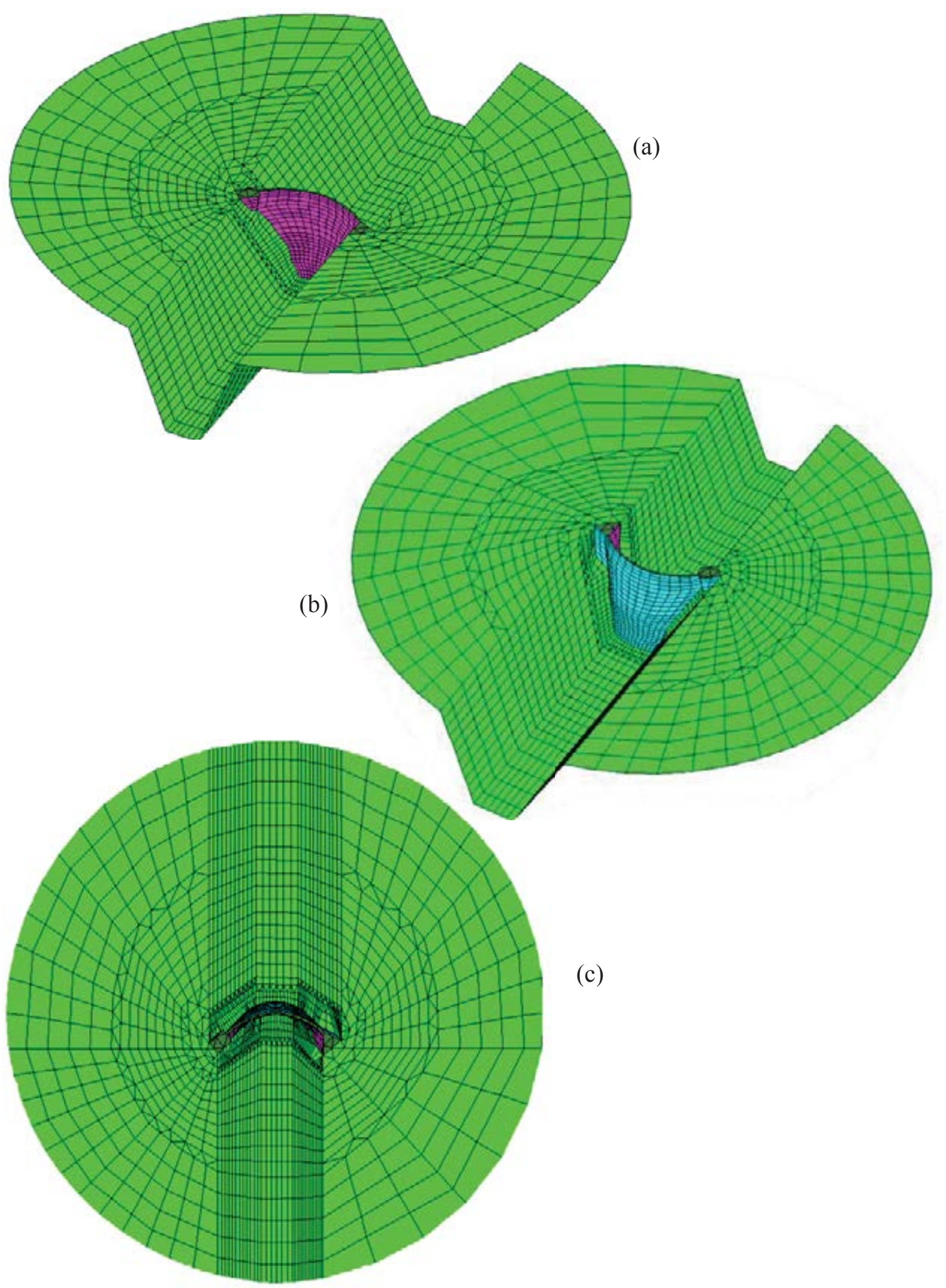

Figure 6: BE model, prismatic canyon. Extension of the free-field discretization: $360 \mathrm{~m}$. (a) Downstream side view, (b) up-stream side view and (c) top view. 


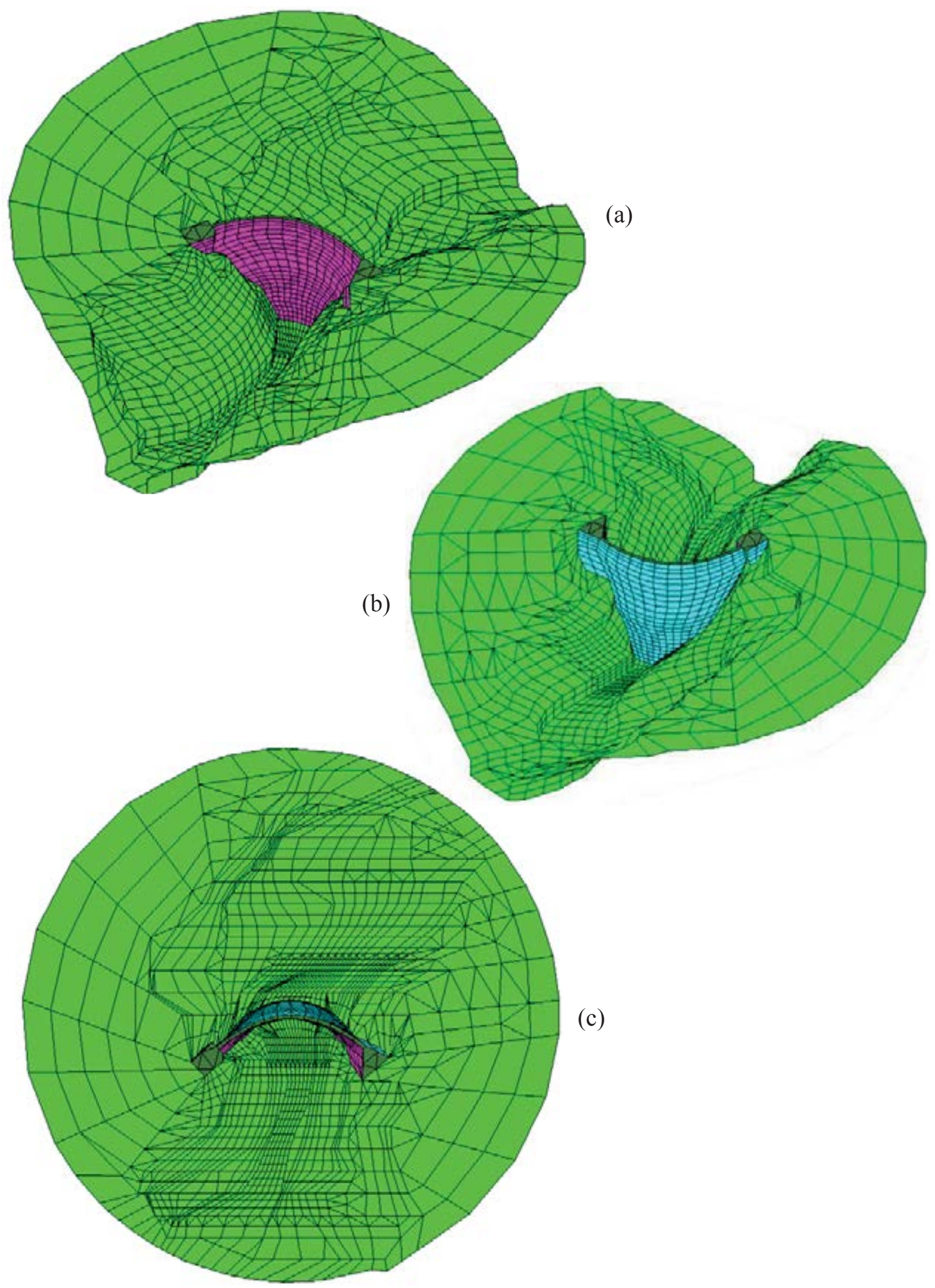

Figure 7: BE model. Approximation of the actual topography of the canyon. Extension of the free-field discretization: 240 m. (a) Downstream side view, (b) upstream side view and (c) top view. 
The nodes studied are node 1 , node 2 and node 3 which are located approximately at $1 / 4$, $1 / 2$ and $3 / 4$ of the dam crest, measured from left to right abutment, respectively (Figure 8). Frequency response functions obtained by BE method in these nodes will be plotted for 4 cases: Fixed-base and compliant-base with different geometries (Figures 5, 6 and 7).

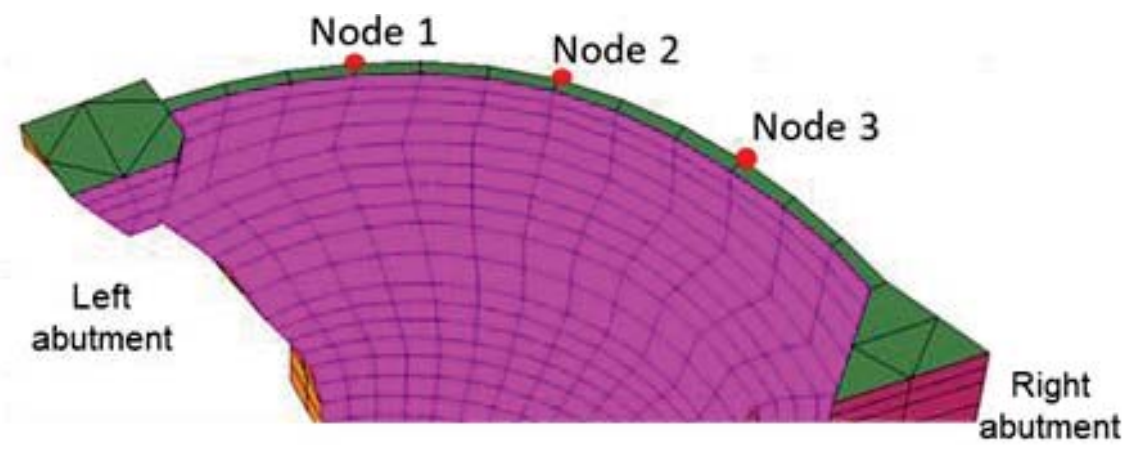

Figure 8: Nodes studied.

On the one hand, in the fixed-base analysis, a unit harmonic horizontal displacement along the up-stream and cross-stream direction was prescribed at the abutments and base of the dam wall (Figure 9.a) ; on the another, for the compliant analysis, the system is assumed to be impinged by seismic time-harmonic plane waves. For this analysis, it was assumed that the incident wave field consists solely of plane $S$ waves propagating vertically with a horizontal upstream and cross-stream free-field ground surface motion [7] (Figure 9.b).
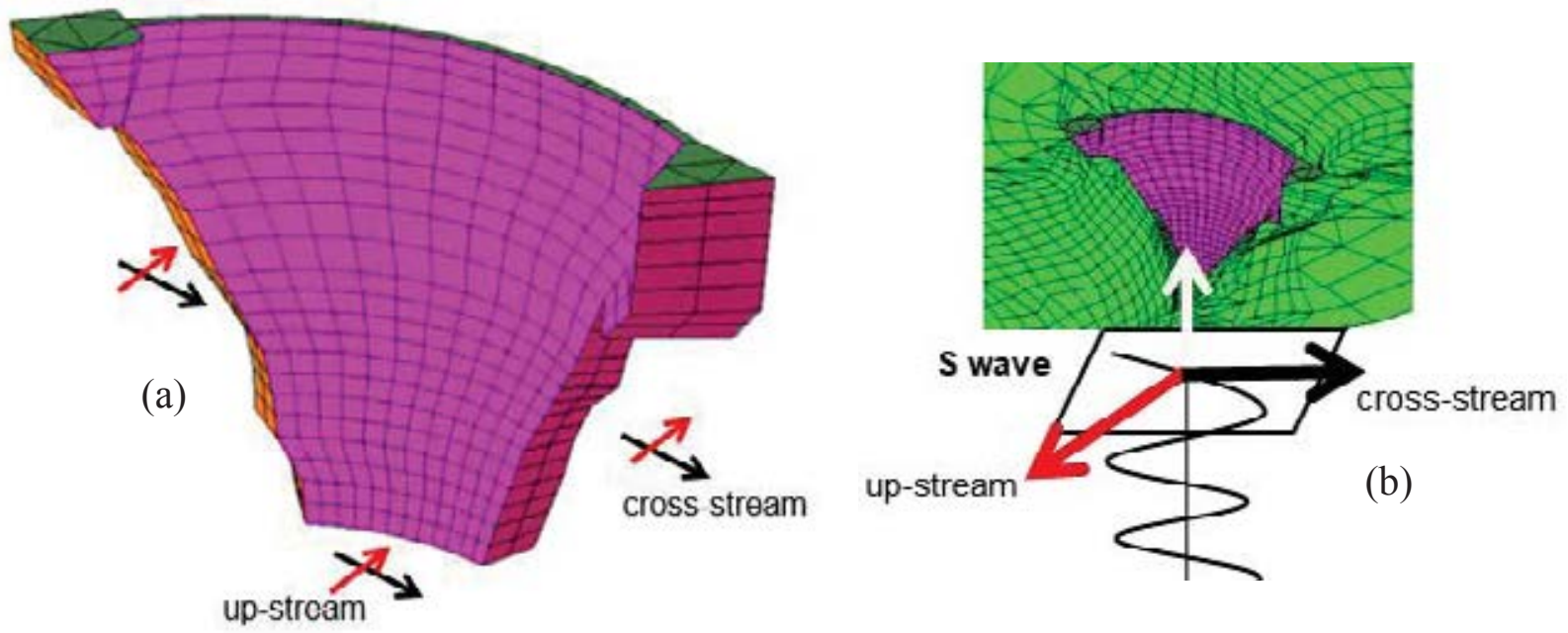

Figure 9: Boundary conditions used in harmonic analyses. (a) Fixed and (b) compliant base.

As mentioned, the concrete dam wall is assumed to be viscoelastic solid with the following properties: density, $\rho=2300 \mathrm{~kg} / \mathrm{m}^{3}$; Poisson's ratio, $v=0.2$; shear modulus, $G=8167 \mathrm{MPa}$ and internal damping, $\xi=0.01$; the foundation rock material is also assumed to be viscoelastic media with a density, $\rho=2143 \mathrm{~kg} / \mathrm{m}^{3}$; Poisson's ratio, $v=0.2$; shear modulus, $G=12083$ $\mathrm{MPa}$ and internal damping, $\xi=0.01[1,7]$. 


\section{ANALYSIS OF RESULTS}

The first four mode shapes and natural vibration frequencies obtained with the finite element modal analysis (FEM) with the fixed-base model, together with the modes infered from the harmonic analysis with the fixed-base model using boundary element method (BEM) are shown in Figure 9 and table 2, respectively.
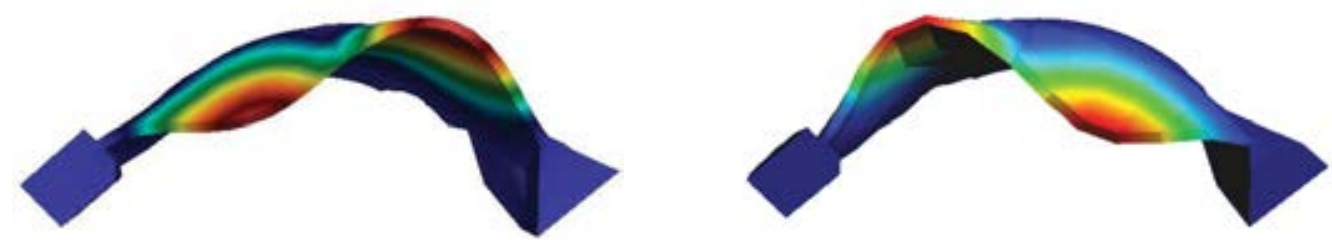

First mode, antisymmetric
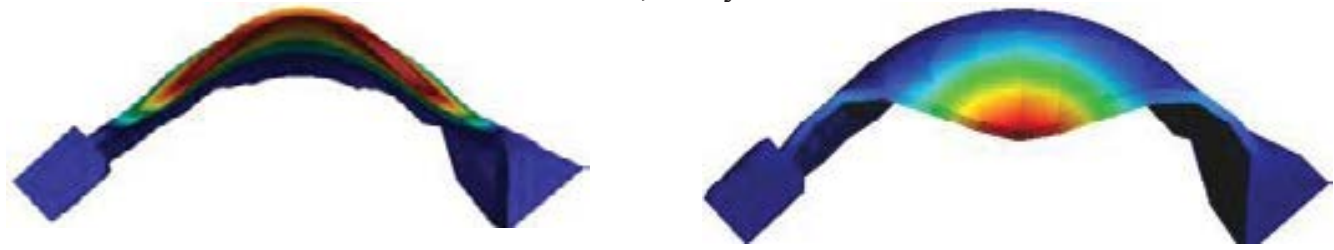

Second mode, symmetric
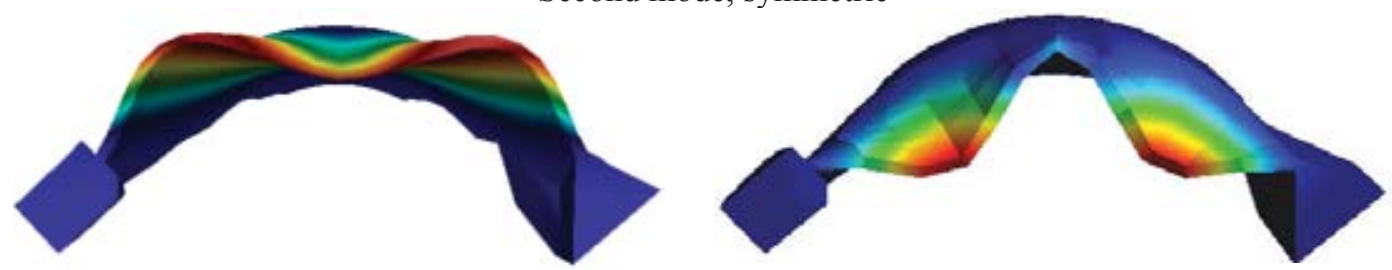

Third mode, symmetric

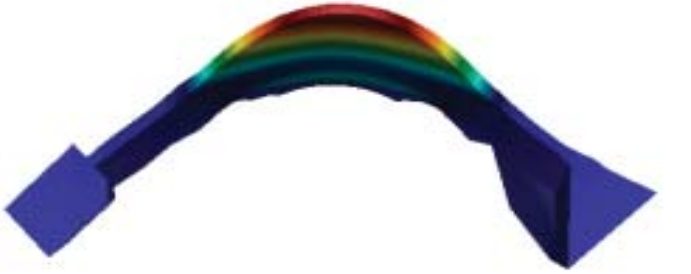

Fourth mode, symmetric

(a)

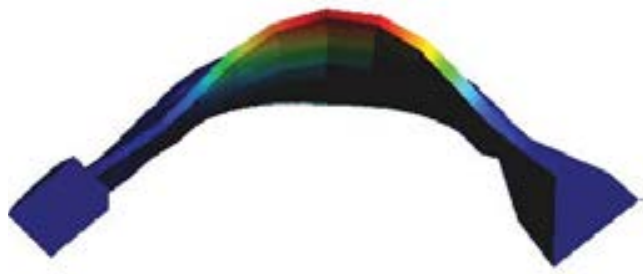

(b)

Figure 9: Mode shapes of vibration: (a) FEM ; (b) BEM.

\begin{tabular}{ccc}
\hline Mode shapes & FEM & BEM \\
\hline First mode & $3,99 \mathrm{~Hz}$ & $4,00 \mathrm{~Hz}$ \\
Second mode & $4,99 \mathrm{~Hz}$ & $5,00 \mathrm{~Hz}$ \\
Third mode & $6,37 \mathrm{~Hz}$ & $6,40 \mathrm{~Hz}$ \\
Fourth mode & $7,80 \mathrm{~Hz}$ & $7,80 \mathrm{~Hz}$ \\
\hline
\end{tabular}

Table 2: Fundamental frequencies: FEM and BEM models.

As can be seen, a very good agreement is observed between the two sets of results, in terms of both mode shapes (Figure 8) and fundamental frequencies (table 2) which contributes to validate the $\mathrm{BE}$ wall mesh used below in the fixed and compliant-base harmonic analyses.

The frequency response functions computed for the fixed-base and compliant-base models with different geometries at the nodes studied are plotted in Figures 10 and 11. 


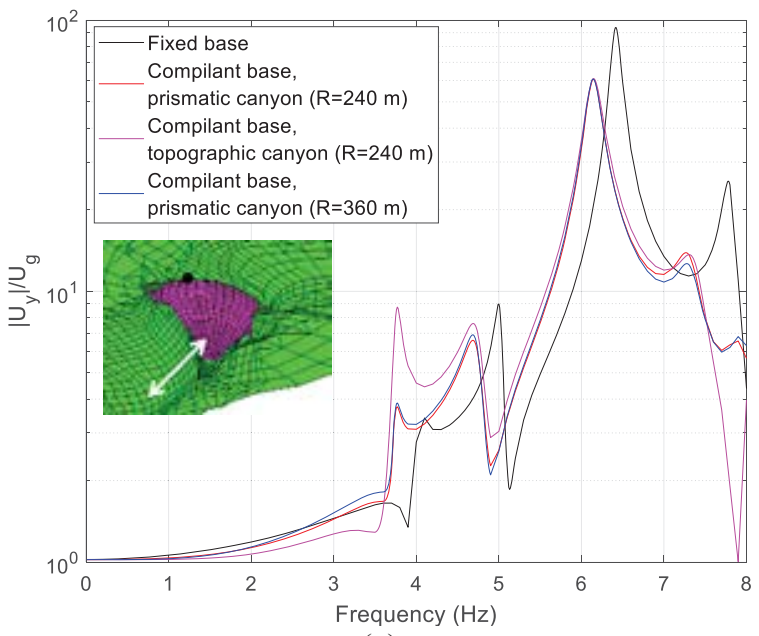

(a)

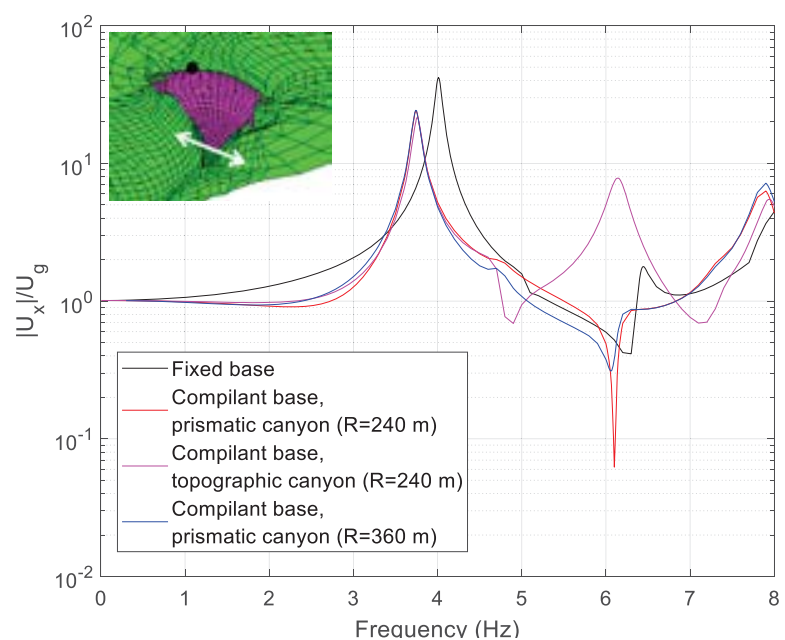

(b)

Figure 10: FRFs. (a) Longitudinal and (b) transversal response of node 1.

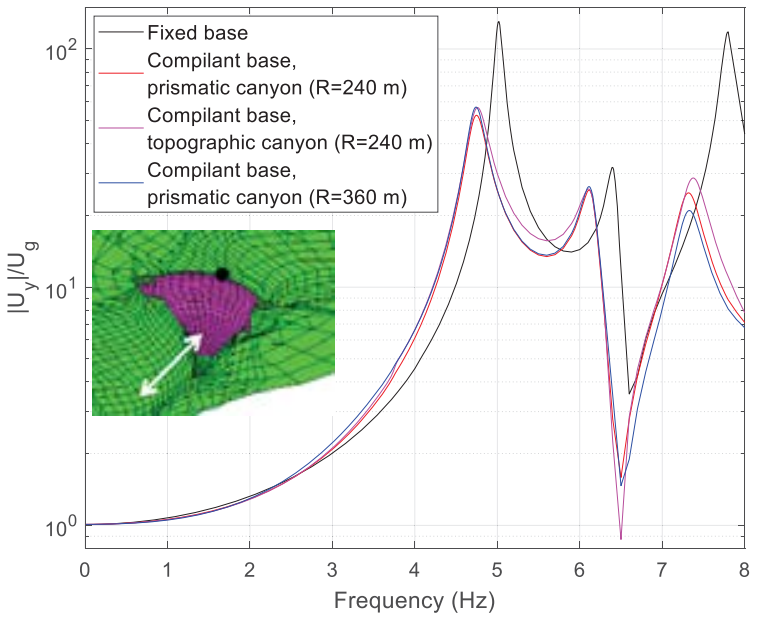

(a)

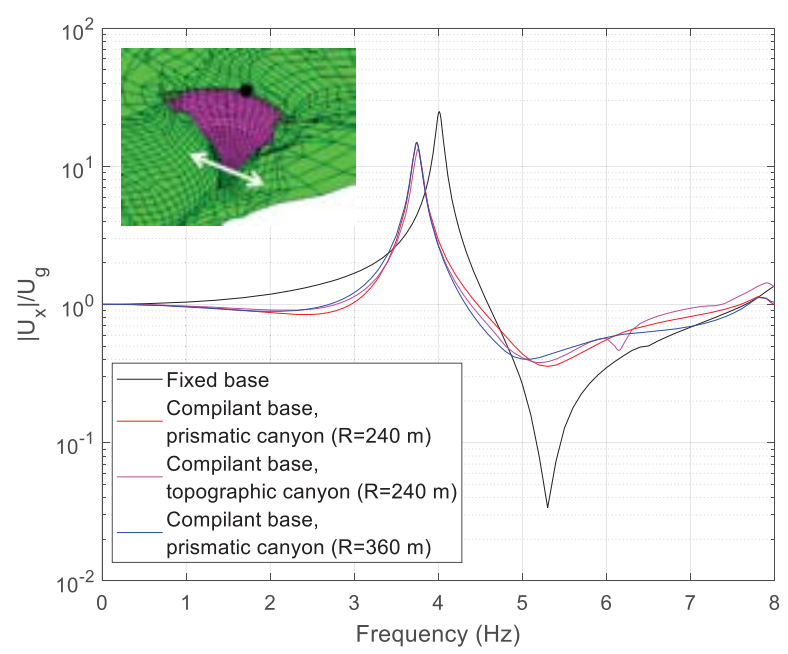

(b)

Figure 11: FRFs. (a) Longitudinal and (b) transversal response of node 2.

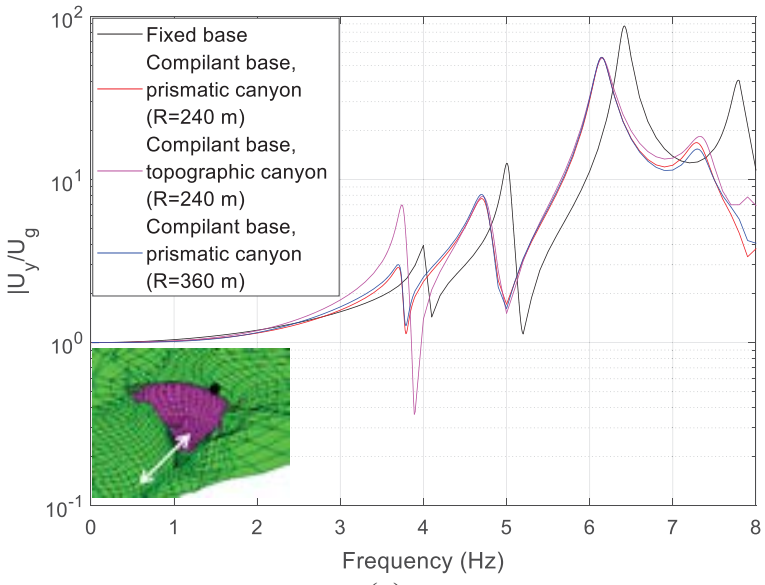

(a)

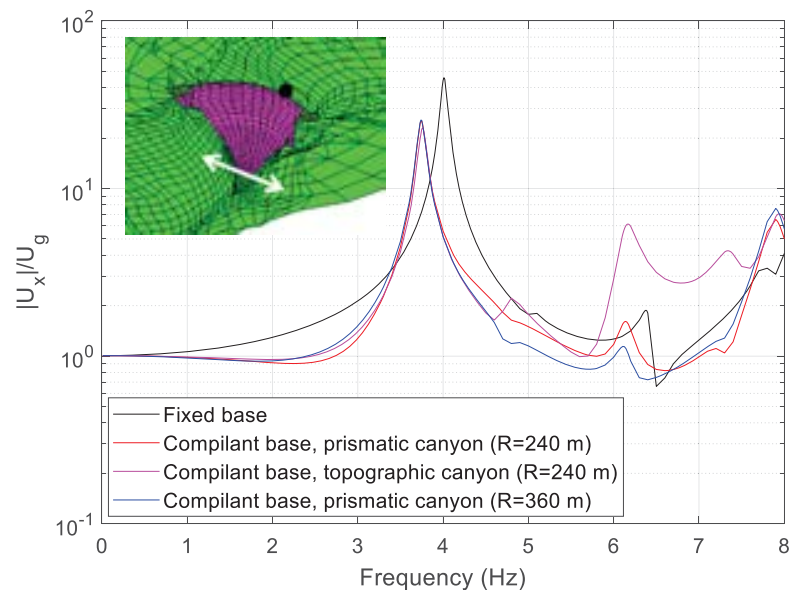

(b)

Figure 12: FRFs. (a) Longitudinal and (b) transversal response of node 3. 


\begin{tabular}{ccccc}
\hline BEM models & $\begin{array}{c}\text { First } \\
\text { frequency }\end{array}$ & $\begin{array}{c}\text { Second } \\
\text { frequency }\end{array}$ & $\begin{array}{c}\text { Third } \\
\text { frequency }\end{array}$ & $\begin{array}{c}\text { Fourth } \\
\text { frequency }\end{array}$ \\
\hline Fixed base & $4.01 \mathrm{~Hz}$ & $5.00 \mathrm{~Hz}$ & $6.44 \mathrm{~Hz}$ & $7.80 \mathrm{~Hz}$ \\
\hline Compilant base, prismatic canyon $(\mathrm{R}=240 \mathrm{~m})$ & $3.74 \mathrm{~Hz}$ & $4.75 \mathrm{~Hz}$ & $6.10 \mathrm{~Hz}$ & $7.32 \mathrm{~Hz}$ \\
\hline Compilant base, topographic canyon $(\mathrm{R}=240 \mathrm{~m})$ & $3.76 \mathrm{~Hz}$ & $4.76 \mathrm{~Hz}$ & $6.14 \mathrm{~Hz}$ & $7.38 \mathrm{~Hz}$ \\
\hline Compilant base, prismatic canyon $(\mathrm{R}=360 \mathrm{~m})$ & $3.74 \mathrm{~Hz}$ & $4.74 \mathrm{~Hz}$ & $6.11 \mathrm{~Hz}$ & $7.33 \mathrm{~Hz}$ \\
\hline
\end{tabular}

Table 3: Fundamental frequencies obtained with harmonic analyses.

As expected, the frequency-domain analyses carried out show that the soil-structure interaction has an important influence on the dynamic response of the dam wall both in amplitude and frequency (Figures 10, 11 and 12, table 3) due to damping character of the soil; as can be observed in table 4, the vibration frequencies on compliant base are between $4.5-6.5 \%$ lower than in fixed base.

\begin{tabular}{ccccc}
\hline Models & $\begin{array}{c}\text { First } \\
\text { frequency }\end{array}$ & $\begin{array}{c}\text { Second } \\
\text { frequency }\end{array}$ & $\begin{array}{c}\text { Third } \\
\text { frequency }\end{array}$ & $\begin{array}{c}\text { Fourth } \\
\text { frequency }\end{array}$ \\
\hline $\begin{array}{c}\text { Compilant base, prismatic canyon } \\
(\mathrm{R}=240 \mathrm{~m})\end{array}$ & $-6.50 \%$ & $-5.00 \%$ & $-4.53 \%$ & $-6.15 \%$ \\
\hline $\begin{array}{c}\text { Compilant base, topographic canyon } \\
(\mathrm{R}=240 \mathrm{~m})\end{array}$ & $-6.00 \%$ & $-4.80 \%$ & $-4.53 \%$ & $-5.38 \%$ \\
\hline $\begin{array}{c}\text { Compilant base, prismatic canyon } \\
(\mathrm{R}=360 \mathrm{~m})\end{array}$ & $-6.50 \%$ & $-5.20 \%$ & $-4.53 \%$ & $-6.02 \%$ \\
\hline
\end{tabular}

Table 4: Fundamental frequencies reduction \%. Compliant base versus to fixed base.

On the other hand, regarding the seismic response of the compliant-base models with different geometrical models of the canyon, it can be seen that while the response of the central node (Figure 11) is mostly unaffected by the level of accuracy of the representation of the topography of the area around the dam wall, the response computed for the most accurate geometrical model for the nodes placed at 1/4 (Figure 10) and 3/4 (Figure 12) of the length of the dam crest show a larger response of the first mode (which is mostly asymmetrical) for the upstream excitation (Figures 10.a and 12.a) and larger response of the third mode (which is mostly symmetrical) for the cross-stream excitation (Figures 10.b and 12.b). This is clearly due to the asymmetry of the topographical representation of the canyon, not present in the first two simplified models of the canyon.

\section{CONCLUSIONS}

In this paper, a boundary element model for the dynamic analysis of coupled systems consisting of solid viscoelastic regions have been applied to the study of the dynamic response of a concrete arch dam taking into account soil-structure interaction.

The frequency-domain analyses carried out show that the soil-structure interaction has an important influence on the seismic response of the dam wall (the vibration frequencies on compliant base are up to $6.50 \%$ lower than in fixed base). It has also been found that the asymmetry of the canyon might affect significantly the seismic response of the dam wall. 
In future studies, numerical models involving structure-soil-water interaction with different reservoir levels will be studied in order to analyze the influence of this interaction on the dam crest, moreover an experimental modal analysis is also planned in order to obtain information for the calibration of the numerical model.

\section{REFERENCES}

[1] Jaime J. González. Presa de Soria. Una historia de proyectos, informes y notas informativas. Gran Canaria 1935-1972. Depósito Legal: GC.562-2010.

[2] INPROES, S.A. and Hermanos Garrote de Marcos, S.A. Documento XYZT de la presa de Soria, 1991.

[3] Infraestructura de Datos Espaciales de Canarias. www.idecanarias.es. 2017.

[4] EDF R\&D, Code_Aster software: Analysis of Structures and Thermomechanics for Studies \& Research, 2017.

[5] O. Maeso, J.J. Aznárez, J. Domínguez. Three-dimensional models of reservoir sediment and effects on seismic response of arch dams. Earthquake Engineering and Structural Dynamics, 33, pp. 1103-1123, 08/2004.

[6] O. Maeso, J.J. Aznárez, J. Domínguez. Effects of space distribution of excitation on seismic response of arch dams. Journal of Engineering Mechanics (ASCE), 128, pp. 759-768, 07/2002.

[7] J. Domínguez, "Boundary elements in dynamics", Southampton, New York, Computational Mechanics Publications \& Elsevier Applied Science; 1993.

[8] Instituto Eduardo Torroja de la construcción - Ministerio de Vivienda (España). Catálogo de Elementos constructivos del Código Técnico de la Edificación, 2010. Disponible

en: $\leq$ https://www.codigotecnico.org/images/stories/pdf/aplicaciones/nCatalog infoEConstr/ CAT-EC-v06.3 marzo_10.pdf $>$ 